\title{
Atendimento Educacional de Crianças e Adolescentes em Condições Complexas de Saúde: uma revisão sistemática
}

\author{
Educational Service of Children and Adolescents in Complex Health
}

Conditions: a Systematic Review

Atención Educativa de Niños y Adolescentes en Condiciones Complejas de

Salud: una revisión sistemática

\section{Mariana Cristina Pedrino}

Doutoranda na Universidade Federal de São Carlos, São Carlos, São Paulo, Brasil.

maripedrino@gmail.com

ORCID - https://orcid.org/0000-0003-0941-4050

Gerusa Ferreira Lourenço

Professora doutora na Universidade Federal de São Carlos, São Carlos, São Paulo, Brasil. gerusa@ufscar.br

ORCID - https://orcid.org/0000-0002-7550-4858

Recebido em 28 de março de 2019

Aprovado em 10 de novembro de 2019

Publicado em 12 de dezembro de 2019

\section{RESUMO}

Nos últimos trinta anos, houve a criação de importantes leis para a proteção e a manutenção dos direitos da infância e da juventude, com ênfase à educação e à saúde. $O$ Atendimento Educacional Especializado marcou um grande avanço nesse aspecto, contemplando as necessidades da escolarização da pessoa com deficiência em ambiente escolar, hospitalar ou domiciliar. Entretanto, as necessidades educativas dos estudantes em condições complexas de saúde, como as condições crônicas, não têm sido contempladas, seja pela falta de clareza dos serviços dessa natureza, pouco elucidados nas legislações pertinentes; ou mesmo pelo desconhecimento da equipe escolar em lidar com as condições desses estudantes. Diante disso, a pesquisa objetiva identificar em âmbito nacional e internacional, que estratégias e ações são tomadas no atendimento educacional de crianças e adolescentes em condições complexas de saúde. Para tanto, foi realizada uma revisão sistemática da literatura, de artigos publicados em periódicos disponíveis online na base de dados Portal de Periódicos da Coordenação de Aperfeiçoamento de Pessoal de Nível Superior (CAPES). Foram selecionados vinte e dois artigos, distribuídos nas seguintes categorias de análise, de acordo com a temática abordada: Preparo e ações da equipe escolar e de saúde; Desafios enfrentados pelos estudantes e/ou equipe escolar; Instrução fora do ambiente escolar e Políticas Públicas. Os resultados reiteram os desafios para a garantia da manutenção e qualidade do processo de escolarização desse público, a necessidade do estabelecimento de apoios integrados entre escola, saúde e família, o que requisita políticas que contemplem a prestação de serviços, além da formação de professores sobre a área.

Palavras-chave: Educação Especial; Condição complexa de saúde; Atendimento educacional. 
http://dx.doi.org/10.5902/1984686X37493

\section{ABSTRACT}

In the last thirty years, laws for the protection and maintenance of the rights of children and youth have been created, with an emphasis on education and health. The Specialized Educational Attendance marked a major breakthrough in this regard, contemplating the schooling needs of the person with disabilities in school, hospital or home environment. However, the educational needs of students in complex health conditions, such as chronic conditions, have not been addressed, either by the lack of clarity of the services of this nature, little elucidated relevant laws; or even the lack of knowledge of the school team in dealing with the conditions of these students. Thus, the research aims to identify national and international strategies and actions are taken on educational care of children and adolescents in complex health conditions. A systematic literature review of articles published in journals available online in the Portal of Periodicals Coordenação de Aperfeiçoamento de Pessoal de Nível Superior (CAPES) was carried out. Twenty-two articles were selected, distributed in the following categories of analysis, according to the theme: Preparation and actions of the school and health team; Challenges faced by students and / or school staff; Instruction outside the school environment and Public Policies. The results reiterate the challenges to guarantee the maintenance and quality of the schooling process of this public, the need to establish integrated support between school, health services and family, which requires policies that contemplate the provision of services, in addition to the training of teachers on the area.

Keywords: Special Education; Complex health conditions; Educational attendance.

\section{RESUMEN}

En los últimos treinta años, ha habido la creación de importantes leyes para la protección y el mantenimiento de los derechos de la niñez y la juventud, con énfasis en la educación y la salud. La Atención Educativa Especializada marcó un gran avance en ese aspecto, contemplando las necesidades de la escolarización de la persona con discapacidad en ambiente escolar, hospitalario o domiciliar. Sin embargo, las necesidades educativas de los estudiantes en condiciones complejas de salud, como las condiciones crónicas, no han sido contempladas, sea por la falta de claridad de los servicios de esa naturaleza, poco elucidados en las legislaciones pertinentes; o incluso por el desconocimiento del equipo escolar en lidiar con las condiciones de esos estudiantes. La investigación objetiva identificar a nivel nacional e internacional, qué estrategias y acciones se toman en la atención educativa de niños y adolescentes en condiciones complejas de salud. Se realizó una revisión sistemática de la literatura, de artículos publicados en revistas disponibles en línea en la base de datos del Portal de revistas de la Coordenação de Aperfeiçoamento de Pessoal de Nível Superior (CAPES). Se seleccionaron veintidós artículos, distribuidos en las siguientes categorías de análisis, de acuerdo con la temática abordada: Preparación y acciones del equipo escolar y de salud; Desafíos enfrentados por los estudiantes y / o equipo escolar; Instrucción fuera del ambiente escolar y Políticas Públicas. Los resultados reiteran los desafíos para la garantía del mantenimiento y calidad del proceso de escolarización de ese público, la necesidad del establecimiento de apoyos integrados entre escuela, salud y familia, lo que requiere políticas que contemplen la prestación de servicios, además de la formación de profesores sobre el área.

Palabras clave: Educación Espéciale; Complejas de salud; Atención educativa. 


\section{Introdução}

Nos últimos trinta anos, em decorrência dos movimentos sociais nacionais e internacionais e das ações do poder público, houve a criação de importantes leis para a proteção e a manutenção dos direitos da infância e da juventude, em especial, no que diz respeito à educação e à saúde. Podemos citar a "Conferência Mundial de Educação para Todos", realizada em Jomtien no ano de 1990 (UNESCO, 1990), que destaca os altos índices de crianças, adolescentes e jovens sem escolarização, chamando a atenção para necessidade de transformações nos sistemas de ensino, com vistas a assegurar o acesso e a permanência de todos na escola. A Declaração Mundial de Educação para Todos (UNESCO, 1990), a Declaração de Salamanca (UNESCO, 1994) e a Convenção de Guatemala (BRASIL, 1999) representam importantes marcos no âmbito da educação mundial, com ênfase para a educação inclusiva.

No Brasil, tivemos a aprovação do Estatuto da Criança e do Adolescente (BRASIL, 1990), reforçando os dispositivos legais já mencionados na Constituição Federal (BRASIL, 1988), e a Lei de Diretrizes de Bases da Educação Nacional (BRASIL, 1996), que preconiza que os sistemas de ensino devem atender às necessidades dos escolares, assegurando currículo, métodos, recursos e organização para essa finalidade. Em decorrência disso, é criada no Brasil a Resolução CNE/CEB nํ2/2001, que estabelece as Diretrizes Nacionais para a Educação Especial na Educação Básica (BRASIL, 2001), define o Atendimento Educacional Especializado - AEE - com caráter complementar ou suplementar à escolarização. Em seu Art. 13, prevê a necessidade de organizar o AEE aos alunos impossibilitados de frequentar as aulas em razão de tratamento de saúde, com internação hospitalar, atendimento ambulatorial ou permanência prolongada em domicílio, com vistas à continuidade de seu processo de desenvolvimento e de aprendizagem, também contribuindo para seu retorno ao convívio escolar.

Pode-se afirmar que um dos grandes desafios das escolas é assistir aos alunos em suas mais diversas necessidades especiais. As que estão relacionadas às deficiências têm sido mais comumente contempladas com algumas adequações. Entretanto, os estudantes em situações complexas de saúde não têm recebido "oportunidades educacionais adequadas" e suas "especificidades de saúde" não têm sido respeitadas no ambiente escolar (BRAGA; BOMFIM; SABBAG FILHO, 2012, p. 432). Além disso, há poucas pesquisas dedicadas à análise dos contextos e da efetivação do Atendimento 
http://dx.doi.org/10.5902/1984686X37493

Pedagógico Domiciliar, importante serviço para os estudantes que não podem frequentar fisicamente a escola por motivos de saúde (MOREIRA; SALLA, 2018).

Além disso, o Decreto no 7.611 de 2011 (BRASIL, 2011) que dispõe sobre a Educação Especial, o Atendimento Educacional Especializado e dá outras providências, em seu Art. 1ํㅗ $\S 1^{\circ}$, restringiu o público-alvo da Educação Especial a: "pessoas com deficiência, com transtornos globais do desenvolvimento e com altas habilidades ou superdotação". Não há menção acerca do aluno em condições temporárias devido ao tratamento de saúde - visto que não se encaixa na categoria de pessoa com deficiência o que anulou a responsabilidade e o tipo de atendimento educacional a ser ofertado para esse público.

No documento construído pela Organização Pan-Americana de Saúde (2012), definem-se condições de saúde como as "circunstâncias na saúde das pessoas que se apresentam de forma mais ou menos persistentes e que exigem respostas sociais reativas ou proativas, episódicas ou contínuas e fragmentadas ou integradas” (p.3). Essas condições vão além de doenças por incorporar certos estados fisiológicos e os acompanhamentos dos ciclos de vida. Nesse sentido, podem se referir aos estados agudos e crônicos, estes caracterizando as condições complexas de saúde.

Compreende-se que a condição de saúde e de doença do estudante, interfere no desenvolvimento do seu estado biológico, bem como nas dimensões emocionais, psíquicas, sociais e educativas. Também interfere na organização e estrutura familiar, pois além de conviver com a doença e seus sintomas, é preciso conviver com os procedimentos e tratamentos (CASTRO; PICCININI, 2002; HOLANDA, 2008; KUCZYNSKI, 2002; NASCIMENTO, 2003; PILGER; SCHROEDER ABREU, 2007).

É preciso compreender as necessidades e os desafios educacionais de estudantes em condições complexas de saúde, a fim de proporcionar oportunidades educacionais mais coerentes e significativas, além de tentar minimizar o impacto em sua escolarização em decorrência dessas condições. Muitas vezes, seu desempenho acadêmico pode ser alterado pela privação de experiências diversas que as outras crianças estejam vivenciando na escola e fora dela, ou pela pouca autonomia e independência na realização de atividades, devido às limitações impostas pela condição crônica.

Além disso, os educadores precisam conhecer as condições de saúde e seus efeitos no desenvolvimento e comportamento do estudante, identificar as necessidades especiais de saúde e as educacionais, pensando em um plano com adaptação e implementação de 
http://dx.doi.org/10.5902/1984686X37493

estratégias e recursos apropriados; bem como a determinação para uso de auxílios e serviços suplementares (DePAEPE; GARRISON-KANE; DOELLING, 2002).

Há estudos que abordam a temática da criança nessas condições, porém a concentração dos mesmos está pautada na área da saúde, principalmente com o enfoque sobre a tipologia das doenças e condições, a importância do diagnóstico precoce, os cuidados e as implicações dos tratamentos para os pacientes com doenças crônicas e seus familiares, sem se debruçarem quanto à oferta de serviços e práticas pedagógicas voltadas a esse público (HOLANDA, 2008; KUCZYNSKI, 2002; NASCIMENTO, 2003; PILGER; SCHROEDER ABREU, 2007).

Diante do exposto, a pesquisa teve como objetivo identificar, em âmbito nacional e internacional, que estratégias e ações são tomadas para proporcionar 0 atendimento educacional de crianças e adolescentes em condições complexas de saúde.

A pesquisa torna-se relevante no campo do conhecimento científico, pois busca analisar o que tem sido publicado cientificamente a respeito da temática em questão. Além disso, com a sistematização das práticas estabelecidas nos cenários nacional e internacional procura colaborar com as discussões acerca das práticas inclusivas na escolarização dos estudantes em condições complexas de saúde.

\section{Método}

A pesquisa configurou-se como revisão sistemática da literatura, que "permite maximizar o potencial de uma busca, encontrando o maior número possível de resultados de uma maneira organizada" (COSTA; ZOLTOWSKI, 2014, p. 56) Além disso, possibilita uma reflexão crítica e compreensiva sobre os materiais analisados.

Conforme os direcionamentos para a sua realização (COSTA; ZOLTOWSKI, 2014), as buscas ocorreram no campo "busca avançada" nas bases de dados constantes no Portal de Periódico da Coordenação de Aperfeiçoamento de Pessoal de Nível Superior (CAPES), optando-se por artigos revisados por pares. Além disso, como critério de inclusão, foram considerados os artigos nos idiomas português, inglês e espanhol, que possuíssem o arquivo completo disponível para acesso e tratassem sobre as estratégias - consideradas como o planejamento e sugestões de possíveis ações - e/ou as ações propriamente ditas no atendimento educacional de crianças em condições complexas de saúde, abordando a temática no título e/ou resumo. Foram excluídos os artigos que não contemplaram esses critérios e aqueles de revisão de literatura. 
A eleição dos termos e as buscas dos artigos no Portal foram realizadas por mais dois juízes pesquisadores na área de processos de escolarização de estudantes em condições complexas de saúde, a fim de validar o processo e garantir a fidedignidade dos dados. Como as buscas foram realizadas em dias diversos, mas dentro do mesmo período (de julho a setembro de 2018), houve pequenas variações no total de trabalhos encontrados, aumentando o número de resultados com alguns termos de busca, visto que diariamente são indexados novos arquivos nas bases. Os mesmos foram acrescentados à planilha para registro e aplicados os critérios de seleção dos mesmos. Com isso, essa variação não comprometeu os resultados para a seleção e análise dos trabalhos.

Nas Tabelas a seguir (1, 2 e 3), são apresentados os termos e combinações utilizados nas buscas por idioma (português, inglês e espanhol, respectivamente), o total de trabalhos advindos pelos indexadores, o total daqueles com os filtros aplicados da própria plataforma (ser artigo, revisados por pares e nos idiomas de busca) e os trabalhos selecionados, considerando os critérios de inclusão e exclusão.

Tabela 1 - Registro da busca de artigos por termos em português

\begin{tabular}{|c|c|c|c|c|c|c|}
\hline Busca & $1 \%$ termo & Booleano & $2^{\circ}$ termo & Resultado & $\begin{array}{l}\text { Com os } \\
\text { filtros }\end{array}$ & Seleção \\
\hline $\begin{array}{l}\text { Qualquer, } \\
\text { (é) exato }\end{array}$ & $\begin{array}{c}\text { estudantes com } \\
\text { doenças } \\
\text { crônicas }\end{array}$ & - & - & 1 & 1 & 1 \\
\hline $\begin{array}{l}\text { Qualquer, } \\
\text { (é) exato }\end{array}$ & $\begin{array}{l}\text { estudantes com } \\
\text { condições } \\
\text { complexas de } \\
\text { saúde }\end{array}$ & - & - & 0 & 0 & 0 \\
\hline $\begin{array}{l}\text { Qualquer, } \\
\text { (é) exato }\end{array}$ & $\begin{array}{l}\text { crianças com } \\
\text { condições } \\
\text { complexas de } \\
\text { saúde }\end{array}$ & - & - & 0 & 0 & 0 \\
\hline $\begin{array}{l}\text { Qualquer, } \\
\text { contém }\end{array}$ & $\begin{array}{c}\text { condições crônicas } \\
\text { de saúde }\end{array}$ & AND & $\begin{array}{c}\text { atendimento } \\
\text { educacional para } \\
\text { crianças com } \\
\text { doenças crônicas }\end{array}$ & 69 & 18 & 2 \\
\hline $\begin{array}{l}\text { Qualquer, } \\
\text { contém }\end{array}$ & $\begin{array}{c}\text { condições } \\
\text { complexas de } \\
\text { saúde }\end{array}$ & AND & $\begin{array}{l}\text { atendimento } \\
\text { educacional }\end{array}$ & 145 & 42 & 1 \\
\hline $\begin{array}{l}\text { Qualquer, } \\
\text { contém }\end{array}$ & $\begin{array}{l}\text { condições } \\
\text { complexas de } \\
\text { saúde }\end{array}$ & AND & $\begin{array}{c}\text { atendimento } \\
\text { educacional para } \\
\text { crianças em } \\
\text { tratamento de } \\
\text { saúde }\end{array}$ & 82 & 10 & 2 \\
\hline $\begin{array}{l}\text { Qualquer, } \\
\text { contém }\end{array}$ & doenças crônicas & AND & $\begin{array}{c}\text { atendimento } \\
\text { educacional para } \\
\text { crianças com } \\
\text { doenças crônicas }\end{array}$ & 86 & 23 & 0 \\
\hline
\end{tabular}




\section{http://dx.doi.org/10.5902/1984686X37493}

Tabela 1 - Registro da busca de artigos por termos em português

\begin{tabular}{|c|c|c|c|c|c|c|}
\hline $\begin{array}{l}\text { Qualquer, } \\
\text { contém }\end{array}$ & $\begin{array}{l}\text { condições } \\
\text { crônicas de } \\
\text { saúde }\end{array}$ & AND & $\begin{array}{l}\text { atendimento } \\
\text { educacional } \\
\text { para crianças } \\
\text { com doenças } \\
\text { crônicas e } \\
\text { condições } \\
\text { incapacitantes }\end{array}$ & 9 & 1 & 0 \\
\hline $\begin{array}{l}\text { Qualquer, } \\
\text { contém }\end{array}$ & $\begin{array}{l}\text { crianças com } \\
\text { doenças } \\
\text { crônicas }\end{array}$ & AND & escolarização & 40 & 23 & 3 \\
\hline $\begin{array}{l}\text { Qualquer, } \\
\text { contém }\end{array}$ & $\begin{array}{l}\text { condições } \\
\text { complexas de } \\
\text { saúde }\end{array}$ & AND & escolarização & 138 & 36 & 0 \\
\hline $\begin{array}{l}\text { Qualquer, } \\
\text { contém }\end{array}$ & $\begin{array}{l}\text { estudantes com } \\
\text { doenças } \\
\text { crônicas }\end{array}$ & AND & $\begin{array}{c}\text { atendimento } \\
\text { educacional } \\
\text { para estudantes } \\
\text { com doenças } \\
\text { crônicas }\end{array}$ & 60 & 10 & 0 \\
\hline
\end{tabular}

Fonte: Elaborado pelas autoras.

Tabela 2 - Registro da busca de artigos por termos em inglês

\begin{tabular}{|c|c|c|c|c|c|c|}
\hline Busca & 1ำ termo & Booleano & 2o termo & Resultado & $\begin{array}{l}\text { Com os } \\
\text { filtros }\end{array}$ & Seleção \\
\hline $\begin{array}{l}\text { Qualquer, (é) } \\
\text { exato }\end{array}$ & $\begin{array}{l}\text { students with } \\
\text { chronic illness }\end{array}$ & - & - & 117 & 14 & 6 \\
\hline $\begin{array}{l}\text { Qualquer, (é) } \\
\text { exato }\end{array}$ & $\begin{array}{l}\text { students with } \\
\text { chronic } \\
\text { diseases }\end{array}$ & - & - & 65 & 9 & 3 \\
\hline $\begin{array}{l}\text { Qualquer, (é) } \\
\text { exato }\end{array}$ & $\begin{array}{l}\text { students with } \\
\text { complex health } \\
\text { conditions }\end{array}$ & - & - & 1 & 0 & 0 \\
\hline Zualquer, contém & $\begin{array}{l}\text { complex health } \\
\text { conditions }\end{array}$ & AND & $\begin{array}{l}\text { educational } \\
\text { assistance for } \\
\text { children with } \\
\text { chronic diseases } \\
\text { and disabling } \\
\text { conditions }\end{array}$ & 831 & 535 & 5 \\
\hline ualquer, contém & $\begin{array}{l}\text { students with } \\
\text { chronic illness }\end{array}$ & AND & $\begin{array}{c}\text { educational } \\
\text { assistance for } \\
\text { children with } \\
\text { chronic illness and } \\
\text { disabling conditions }\end{array}$ & 467 & 400 & 8 \\
\hline Lualquer: contém & $\begin{array}{l}\text { students with } \\
\text { chronic } \\
\text { diseases }\end{array}$ & AND & $\begin{array}{c}\text { educational } \\
\text { assistance for } \\
\text { children with } \\
\text { chronic illness and } \\
\text { disabling conditions }\end{array}$ & 294 & 244 & 0 \\
\hline ualquer, contém & $\begin{array}{l}\text { complex health } \\
\text { conditions }\end{array}$ & AND & $\begin{array}{c}\text { educational } \\
\text { assistance for } \\
\text { students with } \\
\text { chronic diseases } \\
\text { and disabling } \\
\text { conditions } \\
\end{array}$ & 524 & 266 & 1 \\
\hline
\end{tabular}

Fonte: Elaborado pelas autoras. 


\section{http://dx.doi.org/10.5902/1984686X37493}

Tabela 3 - Registro da busca de artigos por termos em espanhol

\begin{tabular}{|c|c|c|c|c|c|c|}
\hline Busca & 1은 termo & Booleano & 20 termo & Resultado & $\begin{array}{l}\text { Com os } \\
\text { filtros }\end{array}$ & Seleção \\
\hline $\begin{array}{l}\text { Qualquer, } \\
\text { (é) exato }\end{array}$ & $\begin{array}{l}\text { estudiante con } \\
\text { enfermedad } \\
\text { crónica }\end{array}$ & - & - & 0 & 0 & 0 \\
\hline $\begin{array}{l}\text { Qualquer, } \\
\text { (é) exato }\end{array}$ & $\begin{array}{c}\text { estudiante con } \\
\text { condiciones } \\
\text { complejas de } \\
\text { salud } \\
\end{array}$ & - & - & 0 & 0 & 0 \\
\hline $\begin{array}{l}\text { Qualquer, } \\
\text { (é) exato }\end{array}$ & $\begin{array}{c}\text { ninõs con } \\
\text { condiciones } \\
\text { complejas de } \\
\text { salud }\end{array}$ & - & - & 0 & 0 & 0 \\
\hline $\begin{array}{l}\text { Qualquer, } \\
\text { contém }\end{array}$ & $\begin{array}{l}\text { enfermedad } \\
\text { crónica }\end{array}$ & AND & $\begin{array}{c}\text { atención } \\
\text { educativa para } \\
\text { niños con } \\
\text { enfermedades } \\
\text { crónicas }\end{array}$ & 89 & 27 & 1 \\
\hline $\begin{array}{l}\text { Qualquer, } \\
\text { contém }\end{array}$ & $\begin{array}{l}\text { condiciones } \\
\text { complejas de } \\
\text { salud }\end{array}$ & AND & $\begin{array}{c}\text { atención } \\
\text { educativa para } \\
\text { niños con } \\
\text { enfermedades } \\
\text { crónicas }\end{array}$ & 0 & 0 & 0 \\
\hline $\begin{array}{l}\text { Qualquer, } \\
\text { contém }\end{array}$ & $\begin{array}{l}\text { estudiante com } \\
\text { enfermedad } \\
\text { crónica }\end{array}$ & AND & $\begin{array}{c}\text { atención } \\
\text { educativa para } \\
\text { estudiante con } \\
\text { enfermedades } \\
\text { crónicas }\end{array}$ & 52 & 7 & 2 \\
\hline $\begin{array}{l}\text { Qualquer, } \\
\text { contém }\end{array}$ & $\begin{array}{l}\text { estudiante con } \\
\text { condiciones } \\
\text { complejas de } \\
\text { salud }\end{array}$ & AND & $\begin{array}{c}\text { atención } \\
\text { educativa para } \\
\text { estudiante con } \\
\text { enfermedades } \\
\text { crónicas }\end{array}$ & 19 & 3 & 0 \\
\hline $\begin{array}{l}\text { Qualquer, } \\
\text { contém }\end{array}$ & $\begin{array}{c}\text { estudiante con } \\
\text { condiciones } \\
\text { complejas de } \\
\text { salud }\end{array}$ & AND & $\begin{array}{c}\text { atención } \\
\text { educativa para } \\
\text { estudiante con } \\
\text { condiciones } \\
\text { complejas de } \\
\text { salud }\end{array}$ & 261 & 132 & 0 \\
\hline $\begin{array}{l}\text { Qualquer, } \\
\text { contém }\end{array}$ & $\begin{array}{l}\text { ninõs con } \\
\text { condiciones } \\
\text { complejas de } \\
\text { salud }\end{array}$ & AND & $\begin{array}{c}\text { atención } \\
\text { educativa para } \\
\text { estudiante con } \\
\text { enfermedades } \\
\text { crónicas }\end{array}$ & 17 & 2 & 0 \\
\hline $\begin{array}{l}\text { Qualquer, } \\
\text { contém }\end{array}$ & $\begin{array}{l}\text { niños con } \\
\text { enfermedad } \\
\text { crónica }\end{array}$ & AND & $\begin{array}{c}\text { atención } \\
\text { educativa para } \\
\text { niños con } \\
\text { enfermedades } \\
\text { crónicas }\end{array}$ & 89 & 27 & 0 \\
\hline $\begin{array}{l}\text { Qualquer, } \\
\text { contém }\end{array}$ & $\begin{array}{c}\text { ninõs con } \\
\text { condiciones } \\
\text { complejas de } \\
\text { salud }\end{array}$ & AND & enseñanza & 166 & 14 & 0 \\
\hline
\end{tabular}

Fonte: Elaborado pelas autoras. 
Foram selecionados 42 trabalhos pelos títulos e resumos. Para analisá-los, as informações foram registradas sucintamente em planilha do Microsoft Excel destacando: títulos e autores, palavras-chave, resumos, objetivos, procedimentos de coleta de dados, participantes e resultados encontrados. Os arquivos foram salvos em um computador e numerados de acordo com a planilha de registro. Todos os artigos selecionados foram lidos na íntegra. A leitura do material compilado foi balizada pelos objetivos do estudo de revisão proposto. Para alcançá-los, foram eliminados aqueles textos que não tratassem especificamente sobre as estratégias e/ou ações no atendimento educacional/escolarização de crianças em condições complexas de saúde, bem como os de revisão de literatura, conforme critérios de exclusão. Também não foram listados os textos que tratavam sobre decisões judiciais acerca da garantia do direito ao atendimento escolar de estudantes com doença crônica, bem como aqueles que versavam sobre as terapias não farmacológicas indicadas para o tratamento desses estudantes em contextos gerais, que não os escolares. Sendo assim, permaneceram como amostra final da revisão realizada 22 trabalhos como apresentado na Figura 1.

Figura 1 - Resultados da revisão

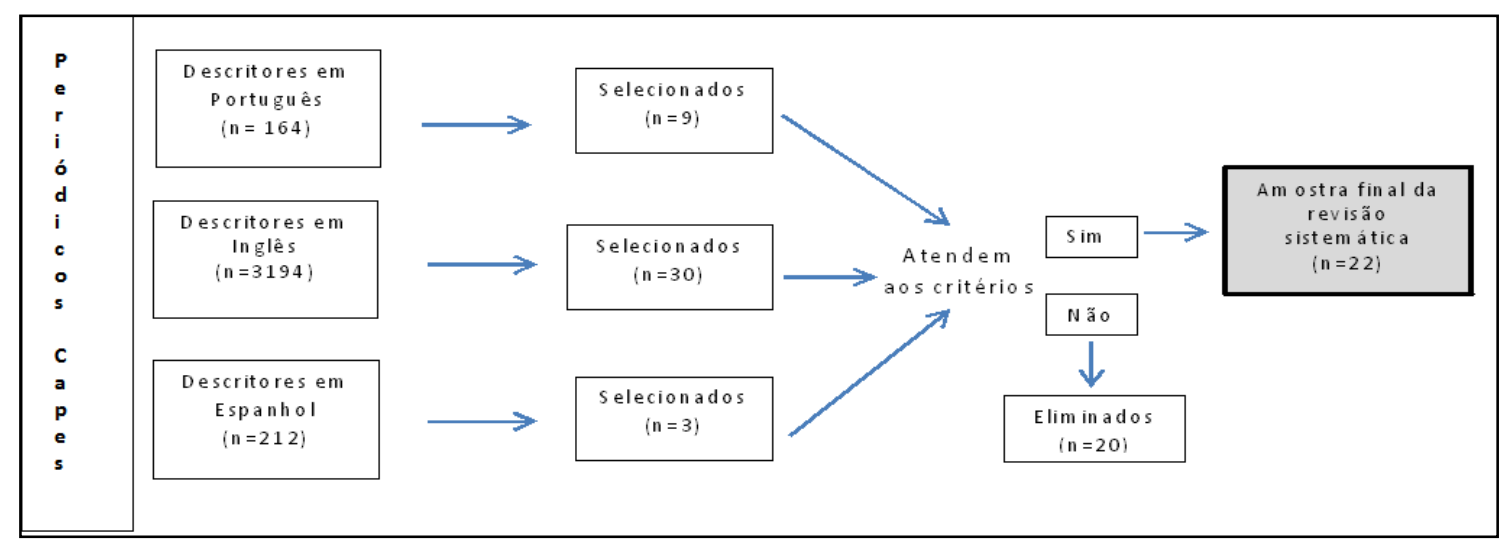

Fonte: Elaborado pelas autoras.

\section{Resultados e discussões}

Os 22 trabalhos selecionados para compor as análises da presente pesquisa estão dispostos na Tabela 4, com destaque para o ano e o periódico de publicação. 
Tabela 4 - Arquivos analisados

\begin{tabular}{|c|c|c|}
\hline Periódico & $\begin{array}{l}\text { Ano de } \\
\text { Publicação }\end{array}$ & Autores \\
\hline British Medical Journal (Reino Unido) & 1990 & $\begin{array}{l}\text { LARCOMBE, I. J.; WALKER, J.; CHARLTON, A; } \\
\text { MELLER, S; MORRIS JONES, P.; MOTT, M. G. }\end{array}$ \\
\hline Journal of School Health (EUA) & 1999 & THIES, K. M. \\
\hline Pediatrics (EUA) & $2000 a$ & $\begin{array}{l}\text { AMERICAN ACADEMY OF PEDIATRICS } \\
\text { Committee on Pediatric AIDS AMERICAN }\end{array}$ \\
\hline Pediatrics (EUA) & $2000 b$ & $\begin{array}{l}\text { ACADEMY OF PEDIATRICS } \\
\text { Committee on School Health }\end{array}$ \\
\hline $\begin{array}{l}\text { International Journal of Disability, } \\
\text { Development \& Education (Reino } \\
\text { Unido) }\end{array}$ & 2001 & SHIU, S. \\
\hline $\begin{array}{l}\text { Revista Latino-Americana de } \\
\text { Enfermagem (Brasil) }\end{array}$ & 2002 & VIEIRA, M. A.; LIMA, R. A. G. de. \\
\hline $\begin{array}{l}\text { Australian Journal of Education } \\
\text { (Austrália) }\end{array}$ & 2004 & SHIU, S. \\
\hline $\begin{array}{l}\text { Australian Journal of Early Childhood } \\
\text { (Austrália) }\end{array}$ & 2004 & ASHTON, J.; BAILEY, J. \\
\hline $\begin{array}{l}\text { Archives of Disease in Childhood } \\
\text { (Reino Unido) }\end{array}$ & 2004 & SURIS, J. C.; MICHAUD, P. A.; VINER, R. \\
\hline Professional School Counseling (EUA) & 2006 & KAFFENBERGER, C. J. \\
\hline Journal of School Health (EUA) & 2008 & TARAS, H.; BRENNAN, J. J. \\
\hline $\begin{array}{l}\text { Revista da Escola de Enfermagem da } \\
\text { USP (Brasil) }\end{array}$ & 2011 & HOLANDA, E. R. de; COLLET, N. \\
\hline Professional School Counseling (EUA) & 2011 & $\begin{array}{l}\text { HAMLET, H. S; GERGAR, P. G.; SCHAEFER, B. } \\
\text { A. }\end{array}$ \\
\hline $\begin{array}{l}\text { Australasian Journal of Special } \\
\text { Education (Austrália) }\end{array}$ & 2012 & WILKIE, K. J. \\
\hline $\begin{array}{l}\text { Revista Brasileira de Educação } \\
\text { Especial }\end{array}$ & 2012 & $\begin{array}{l}\text { BRAGA, T. M. S.; BOMFIM, D. P.; SABBAG } \\
\text { FILHO, D. }\end{array}$ \\
\hline Revista Educación (Costa Rica) & 2013 & BARRIOS-HERNANDEZ, Y. \\
\hline $\begin{array}{l}\text { Revista CEFAC: Atualização Científica } \\
\text { em Fonoaudiologia e Educação } \\
\text { (Brasil) }\end{array}$ & 2014 & $\begin{array}{l}\text { MOURA, R. G. F.; BATISTA, A. A.; COBE, G. } \\
\text { M.; FERREIRA, C. L.; MELO, P. D. F.; MAIA, E. } \\
\text { M. C. }\end{array}$ \\
\hline Academic Pediatrics (EUA) & 2015 & $\begin{array}{l}\text { GOLDFELD, S.; O'CONNOR, M.; QUACH, J.; } \\
\text { TARASUIK, J.; KVALSVIG, A. }\end{array}$ \\
\hline $\begin{array}{l}\text { Revista de Psicología del Deporte } \\
\text { (Espanha) }\end{array}$ & 2016 & $\begin{array}{l}\text { GELABERT, S. V.; RAMON, M. R. R.; MAYOL, } \\
\text { B. de L. I. }\end{array}$ \\
\hline Revista Periferia (Brasil) & 2017 & $\begin{array}{l}\text { NASCIMENTO, F. F. do; YAAKOUB, M. C.; } \\
\text { AQUINO, C. M. }\end{array}$ \\
\hline $\begin{array}{l}\text { Revista Brasileira em Promoção da } \\
\text { Saúde (Brasil) }\end{array}$ & 2017 & $\begin{array}{l}\text { GARCIA, L. R. S.; ARAÚJO, T. D. V. G.; SILVA, } \\
\text { P. G. O. da; MEDEIROS, H. G. S. de; BARROS, } \\
\text { S. S. de; GARCIA, L. C. S. }\end{array}$ \\
\hline Journal of School Health (EUA) & 2018 & $\begin{array}{l}\text { BERGER, C.; VALENZUELA, J.; TSIKIS, J.; } \\
\text { FLETCHER, C. }\end{array}$ \\
\hline
\end{tabular}

Fonte: Elaborado pelas autoras. 
http://dx.doi.org/10.5902/1984686X37493

Dos artigos selecionados apenas dois foram publicados na década de 1990, sendo um em seu início e o outro ao final, e os demais estão distribuídos ao longo dos anos 2000, sem haver uma concentração em ano específico, o que pode indicar uma manutenção no fluxo de publicações que abordam essa temática.

Conforme Tabela 4, há oito artigos em periódicos norte-americanos, sendo dois específicos da área da saúde: Pediatrics e Academic Pediatrics. Há uma revista que apresenta trabalhos exclusivos da saúde dos estudantes nas escolas, Journal of School Health. Por fim, há um periódico que faz a cobertura de temáticas sobre a profissão de aconselhamento escolar, denominado Professional School Counseling. O periódico australiano Australian Journal of Early Childhood aborda o campo da primeira infância, considerando os aspectos da educação, saúde, cuidados e desenvolvimento. Já o Australian Journal of Education é uma revista que publica artigos no campo da educação e o periódico Australasian Journal of Special Education, traz artigos sobre a Educação Especial. Há dois periódicos britânicos que são da área da saúde, British Medical Journal e o periódico Archives of Disease in Childhood que cobre o campo da pediatria. O terceiro periódico, International Journal of Disability, Development \& Education, tem um enfoque sobre a educação e o desenvolvimento de pessoas com deficiência. O periódico espanhol Revista de Psicología del Deporte publica trabalhos no campo da psicologia do desporto, aceitando trabalhos que propõem a interdisciplinaridade entre as Ciências da Atividade Física e o Esporte. A Revista Educación, da Universidade de Costa Rica é destinada à publicação de artigos relacionados à educação de uma forma geral: acesso, permanência e práticas inclusivas.

Das publicações brasileiras, três periódicos são da área da saúde - Revista LatinoAmericana de Enfermagem, Revista da Escola de Enfermagem da USP e Revista Brasileira em Promoção da Saúde - e duas da área da educação, sendo um da Educação Especial - Revista Periferia e Revista Brasileira de Educação Especial. Há ainda uma revista que abrange as duas áreas (saúde e educação) - Revista CEFAC: Atualização Científica em Fonoaudiologia e Educação.

Qualitativamente, considerando os temas abordados pelos artigos, optou-se pela organização e análise dos textos selecionados em categorias temáticas, na tentativa de responder ao objetivo dessa pesquisa, distribuídos conforme Tabela 5: 
http://dx.doi.org/10.5902/1984686X37493

Tabela 5 - Distribuição dos artigos por categorias de análise temática

\begin{tabular}{|l|c|}
\hline \multicolumn{1}{|c|}{ Categoria } & Qtd artigos \\
\hline 1) Desafios enfrentados pelos estudantes e/ou equipe escolar & 9 \\
\hline 2) Preparo e ações da equipe escolar e de saúde & 9 \\
\hline 3) Instrução fora do ambiente escolar & 3 \\
\hline 4) Políticas Públicas & 1 \\
\hline
\end{tabular}

Fonte: elaborado pelas autoras.

$\mathrm{Na}$ primeira categoria denominada "Desafios enfrentados pelos estudantes e/ou equipe escolar", nove pesquisas trazem mais pontualmente a problemática do impacto das condições complexas de saúde na vivência das crianças e dos adolescentes no âmbito escolar, bem como os desafios que a equipe escolar sinaliza diante dessa realidade (AMERICAN ACADEMY OF PEDIATRICS, 2000a; BERGER et al., 2018; GOLDFELD et al., 2015; KAFFENBERGER, 2006; MOURA et al., 2014; NASCIMENTO; YAAKOUB; AQUINO, 2017; SHIU, 2001; 2004; SURIS; MICHAUD; VINER; 2004).

A declaração do Committee on Pediatric AIDS da American Academy of Pediatrics (2000a) indica que crianças e jovens com infecção pelo HIV podem necessitar de serviços especiais, incluindo instrução domiciliar, como os estudantes com outras doenças crônicas. Recomenda-se haver uma educação apropriada para todo o pessoal da escola, bem como a comunicação dos profissionais de saúde, a fim de organizar a escola para a manutenção da saúde dos estudantes, bem como para proporcionar o senso de pertencimento e normalidade à realidade escolar. Ainda, que a equipe escolar conheça as manifestações de doenças crônicas atribuíveis à infecção pelo HIV, para que possa fornecer programas educacionais apropriados.

Berger et al. (2018) descrevem as necessidades de educadores em trabalhar com alunos com doenças crônicas. Selecionaram os participantes do estudo em dois municípios da região sudeste dos Estados Unidos, com aproximadamente 170 escolas de ensino fundamental e médio. Há consenso entre os participantes de que é necessária a colaboração entre a equipe de saúde, as escolas e as famílias; mas há dissenso sobre os desafios que os alunos com doenças crônicas enfrentam nas escolas, dificultando a eleição dos apoios necessários. Pelos questionários, os participantes relataram sentir-se menos preparados para trabalhar com estudantes que apresentavam fibrose cística, epilepsia ou doença falciforme. Essas doenças parecem ser bastante comuns naquela 
http://dx.doi.org/10.5902/1984686X37493

realidade escolar e as que mais deixam os professores aflitos, considerando suas especificidades e limitações funcionais.

Goldfeld et al. (2015) examinam as vias de aprendizagem de crianças australianas com condições complexas de saúde, tanto as que já possuem o diagnóstico ao ingressarem na escola, quanto àquelas que manifestam tais necessidades no decorrer do período de escolarização. Os dados revelam que ambas possuem desempenho mais insatisfatório no processo de aprendizagem, se comparadas com os pares, independente do grau de complexidade de suas necessidades. Além disso, as crianças que também possuem baixo nível socioeconômico estão mais propensas ao fracasso acadêmico. Os autores sinalizam que a identificação precoce das dificuldades, juntamente com o apoio integrado dos profissionais da saúde e da educação, pode potencializar o percurso educacional dessas crianças.

Kaffenberger (2006) apresenta alguns desafios que as escolas enfrentam para atender alunos com doenças crônicas e suas famílias, e sugere o papel que os conselheiros escolares podem desempenhar na coordenação dos serviços de apoio para aqueles estudantes, facilitando também seu retorno precoce ao ambiente escolar. Dentre os desafios, cita-se a falta de comunicação entre a escola, as famílias e os profissionais da saúde, bem como a falta de treinamento e recursos que viabilizem essa atuação.

Moura et al. (2014) realizam um levantamento dos fatores intrínsecos e extrínsecos que podem interferir no processo de aprendizagem de crianças com epilepsia. Analisando um questionário aplicado aos pais ou cuidadores dessas crianças, os dados demonstram que há elementos que influenciam negativamente seu processo de aprendizagem, como o comprometimento da assiduidade na escola, em virtude das crises, como também a superproteção dos pais.

Na obra de Nascimento; Yaakoub e Aquino (2017) são estudadas as relações da educação e da saúde do sujeito com cardiopatia reumática por meio dos relatos das histórias de vida dos alunos. As autoras identificaram as problemáticas ocasionadas pelo processo de adoecimento, com relação ao acesso à educação e a trajetória escolar desses sujeitos. Constataram que os entrevistados possuem um histórico de reprovações escolares, em decorrência dos longos e dolorosos períodos de afastamento para tratamento. Os pacientes acabam não recebendo a escolarização fora da escola durante período de tratamento, direito garantido pela legislação, o que prejudica seu acompanhamento e permanência na escola, implicando também em dificuldades para a 
http://dx.doi.org/10.5902/1984686X37493

manutenção de vínculos com os colegas e em alguns casos, na inserção no mercado de trabalho.

Shiu (2001) defende a importância de identificar os desafios educacionais enfrentados por estudantes com doenças crônicas, para fornecer orientação para 0 desenvolvimento de programas que atendam não apenas as suas necessidades acadêmicas, mas também as sociais e as emocionais. Com a frequência escolar comprometida, consequentemente, o relacionamento entre os pares e o desempenho escolar são prejudicados. A equipe escolar desempenha um papel fundamental na vida daqueles estudantes, especialmente no retorno precoce à rotina escolar, no interesse e no desempenho acadêmico.

Essa mesma autora (SHIU, 2004) destaca a necessidade de serem compreendidas as complexas questões que cercam a prestação de serviços educacionais para os estudantes com doenças crônicas, para que haja o planejamento, a busca e o fornecimento dos serviços e recursos mais adequados para assegurar acesso igual aos mesmos resultados educacionais que os alunos sem condições crônicas de saúde. Para tanto, investigou quinhentas escolas selecionadas aleatoriamente no estado australiano Nova Gales do Sul quanto às percepções de pais e professores sobre serviços educacionais para estudantes com doenças crônicas. Os dados revelam que as escolas podem fazer a diferença na vida desses estudantes a partir do momento em que apoiam e respondem às suas necessidades nos aspectos educacional, social, físico e emocional. Para tanto, a comunicação é um elemento chave para essa prática, bem como o trabalho baseado na interdisciplinaridade, que encoraja a colaboração entre todos os envolvidos com esse aluno.

Suris; Michaud e Viner (2004) analisam os efeitos das condições complexas de saúde no desenvolvimento psicossocial do adolescente. A gravidade da doença, bem como a adesão ao seu tratamento podem interferir na frequência escolar, o que é um agravante no estabelecimento de vínculos entre os estudantes além dos prejuízos acadêmicos envolvidos. Além disso, a não comunicação dos pais e dos próprios adolescentes, bem como dos profissionais da saúde sobre a doença crônica e seus tratamentos, pode ocasionar a falta de apoio aos alunos, especialmente em eventos críticos, como em uma crise epilética ou diabética, ou ainda no esgotamento físico em decorrência de artrite reumatoide Assim como no trabalho de Nascimento; Yaakoub e Aquino (2017) percebe-se também nesse artigo os impactos das condições complexas de 
http://dx.doi.org/10.5902/1984686X37493

saúde quanto à aprendizagem dos estudantes, influenciando no desenvolvimento de suas trajetórias acadêmicas, marcadas por um baixo desempenho/aproveitamento em relação aos colegas sem doenças crônicas.

A segunda categoria de análise intitulada "Preparo e ações da equipe escolar e de saúde" abrange nove trabalhos que apresentam indicações de estratégias e ações para que a equipe escolar (professores e demais servidores) possa se organizar de modo a atender as demandas dos estudantes em condições complexas de saúde, na tentativa de minimizar os impactos dessas condições, tanto no que diz respeito ao período de afastamento quanto ao retorno do aluno à instituição (BARRIOS-HERNANDEZ; 2013; BRAGA; BOMFIM; SABBAG FILHO, 2012; GARCIA et al., 2017; GELABERT; RAMON; MAYOL, 2016; LARCOMBE et al.,1990; HAMLET; GERGAR; SCHAEFER, 2011; TARAS; BRENNAN, 2008; THIES; 1999; WILKIE; 2012).

Barrios-Hernandez (2013) explica como a doença crônica, especialmente a epilepsia, interfere na qualidade da vida das crianças em idade escolar. Aspectos familiares como a superproteção e o descrédito nas capacidades dessas crianças irão interferir em seu desenvolvimento. É necessário um nível adequado de conhecimento para lidar com as situações diversas desses estudantes, para garantir sua integridade física e psíquica, além de contribuir para uma qualidade de vida favorável. $\mathrm{O}$ autor sugere a prática de esportes e atividades ao ar livre, visto que a atividade física reduz a possibilidade de haver um ataque epilético. Para tanto, os professores de Educação Física necessitam de informações precisas sobre a doença e seu tratamento para que elaborem um plano de atuação visando à melhora na condição e na integração social daqueles estudantes.

A pesquisa de Braga; Bomfim e Sabbag Filho (2012) acrescenta novos elementos sobre a temática, ao discutir as necessidades especiais de saúde dos escolares com Diabetes Mellitus tipo 1, que acabam acarretando dificuldades de aprendizagem e uma série de especificidades que têm grande impacto no cotidiano escolar. As sugestões dos autores para suprir esses desafios seriam a elaboração de planos de cuidados e pequenas adaptações na escola, como mudanças no cardápio ou no horário da merenda escolar, além de ações políticas mais amplas, como a formação de professores e a aproximação entre educação e saúde.

Também sobre Diabetes Mellitus, o artigo de Garcia et al. (2017) descreve o conhecimento de profissionais da rede pública de ensino da cidade de Natal $(R N)$ sobre a 
mesma, o tratamento e as complicações à saúde de pessoas com essa doença. Após aplicação de um questionário aos funcionários, constatou-se que apenas professores conseguem definir a doença e conhecem suas formas de tratamento. Entretanto, há menos conhecimento sobre os cuidados e o manejo da doença, especialmente sobre situações de risco, como a hipoglicemia. Os autores sugerem investir em atividades de educação em saúde, capacitando os profissionais das escolas para que possam oferecer acompanhamento, cuidado e apoio à criança em suas necessidades. Além disso, reforçam que a comunicação entre a escola e a família é essencial para uma maior adesão tanto às recomendações de dieta e exercício físico quanto ao tratamento medicamentoso.

Gelabert; Ramon e Mayol (2016) identificam e analisam tanto os fatores facilitadores quanto os obstáculos para a melhoria da qualidade de vida de estudantes com doenças crônicas na escola. Nesse sentido, apontam para o papel da Educação Física no desenvolvimento e bem-estar desse grupo, como já citado na obra de Barrios-Hernandez (2013). Os resultados indicam que há consenso sobre a presença de um professor mentor comprometido para viabilizar o desenvolvimento emocional e físico daqueles estudantes. Por outro lado, os dados também revelam como obstáculos para a promoção da qualidade de vida: a falta de comunicação entre os profissionais, a escassez de recursos e a não participação daqueles alunos nas atividades e passeios extracurriculares. Os autores propõem a criação de redes de apoio nas escolas para viabilizar as ações de melhoria da vivência dos estudantes com doenças crônicas, contando com profissionais de saúde e psicólogos. Além da comunicação/integração entre família, escola e equipe de saúde, já destacadas nos textos até aqui analisados (BRAGA; BOMFIM; SABBAG FILHO, 2012; GARCIA et al., 2017), a obra em questão indica a necessidade de um profissional encarregado de melhor articular esse processo de interação.

Corroborando, Hamlet; Gergar e Schaefer (2011) investigaram as práticas de escolas e dos conselheiros escolares que trabalham com esses estudantes nos Estados Unidos, bem como os protocolos para a prestação de seus serviços. Há um destaque para o papel dos conselheiros na tentativa de facilitar a integração de serviços, a implementação de programas e o monitoramento das intervenções. Novamente, como já citado nas obras anteriores (BRAGA; BOMFIM; SABBAG FILHO, 2012; GARCIA et al., 2017; GELABERT; RAMON; MAYOL, 2016), ressalta-se a importância da colaboração, da 
http://dx.doi.org/10.5902/1984686X37493

comunicação e da cooperação entre o estudante com doenças crônicas, colegas, pais, profissionais da escola e provedores de cuidados médicos.

Larcombe et al. (1990) inovam ao focar a pesquisa no retorno das crianças à escola, após período prolongado de afastamento para tratamento de saúde. Estudam o impacto psicossocial do tratamento de câncer em crianças, por meio de questionários aplicados a pais e professores, a partir de acompanhamento com grupo controle. Os resultados mostram uma maior variedade de problemas físicos relacionados ao tratamento medicamentoso; seguidos por uma variedade de problemas acadêmicos, muitas vezes em decorrência das ausências e também por problemas psicológicos e comportamentais presentes. Aqui também se tem, como recomendação para facilitar o retorno à escola, o desenvolvimento de uma melhor ligação entre o hospital, a escola e a família (BRAGA; BOMFIM; SABBAG FILHO, 2012; GARCIA et al., 2017; GELABERT; RAMON; MAYOL, 2016; HAMLET; GERGAR; SCHAEFER, 2011). Os autores justificam que a comunicação precisa ser efetiva e constante e algumas práticas podem ser implantadas para evitar o absenteísmo, como por exemplo, alternar os dias e horários de consulta ou de procedimentos. Sugere-se também que a equipe de saúde informe melhor os professores sobre os possíveis problemas físicos, acadêmicos, psicológicos e comportamentais decorrentes da doença ou do tratamento. Essa obra apresenta ações mais efetivas, especialmente por parte da equipe de saúde, na tentativa de minimizar os impactos dos afastamentos e de melhorar a condição dos estudantes na escola.

Taras e Brennan (2008) sinalizam a necessidade de a equipe escolar estar preparada para prevenir, reconhecer e reagir adequadamente às manifestações dos sintomas das condições complexas de saúde dos estudantes. Realizaram uma revisão dos registros de encaminhamentos feitos por escolas do sul da Califórnia (de julho de 1996 a outubro de 2006) para um centro acadêmico que fornece consulta médica. Os dados coletados revelam as atividades empregadas para superar as dificuldades enfrentadas pelas escolas ao receber estudantes com condições especiais de saúde, dentre elas, a comunicação direta com os próprios médicos dos estudantes, que indicam os serviços de saúde escolar quando necessário e auxiliam na formulação de um plano de saúde escolar individualizado aos estudantes. Tal como nas demais pesquisas até aqui analisadas (BRAGA; BOMFIM; SABBAG FILHO, 2012; GARCIA et al., 2017; GELABERT; RAMON; MAYOL, 2016; HAMLET; GERGAR; SCHAEFER, 2011; LARCOMBE et al., 1990), considera-se que a comunicação efetiva entre a equipe escolar 
http://dx.doi.org/10.5902/1984686X37493

e os médicos que fazem o atendimento desses alunos, bem como a capacitação e treinamento de todos da escola, pode evitar alguns inconvenientes, como o absenteísmo e o prejuízo no desempenho acadêmico daqueles.

Thies (1999) também reforça a importância de a equipe escolar estar preparada para identificar as implicações educacionais das doenças crônicas em crianças em idade escolar, oferecendo os serviços necessários antes que os estudantes tenham seu desempenho prejudicado. Destaca-se a importância nesse processo, das parcerias entre famílias, escolas e prestadores de cuidados de saúde na tentativa de minimizar o impacto da doença na vida acadêmica dos estudantes, no mesmo sentido que o trabalho de Taras e Brennan (2008).

Por fim, Wilkie (2012) realiza um estudo com alunos do ensino médio com ausências constantes em decorrência de tratamento de saúde e seus professores de matemática. São indicadas ações que viabilizam a manutenção do processo de ensino e de aprendizagem, mesmo diante da frequência irregular dos alunos, como por exemplo, as videoconferências ou atividades por e-mail. Também são apresentados os empecilhos para que esse processo ocorra como esperado, como a falta de recursos digitais ou de suporte para o uso de Tecnologias de Informação e Comunicação (TIC), ou mesmo da administração do tempo adicional do professor para preparar as práticas diferenciadas ou as interações com um profissional que atue como conselheiro de educação hospitalar, figura importante para o sucesso dessas ações. Essa foi a única pesquisa que realmente analisou a implantação de ações no âmbito educacional para minimizar os prejuízos acadêmicos e sociais de alunos com condições complexas de saúde, e traz indicações de meios para suprir as necessidades de tais estudantes no processo de escolarização.

Já na categoria "Instrução fora do ambiente escolar", três trabalhos indicam as possibilidades de atendimento educacional fora da escola, como em classes hospitalares, em domicílio ou casas de apoio, sinalizando uma importante alternativa para quando há a necessidade de afastamento para internação, tratamento ou quando a condição de saúde se agrava impedindo a permanência no ambiente escolar (AMERICAN ACADEMY OF PEDIATRICS, 2000b; HOLANDA; COLLET, 2011; VIEIRA; LIMA, 2002).

$\mathrm{Na}$ declaração da American Academy of Pediatrics (2000b), há a recomendação de que as crianças e adolescentes em idade escolar, impedidos de frequentar a escola em decorrência de doenças ou lesões agudas e condições médicas crônicas, obtenham sua educação em outros ambientes não escolares, como casas ou hospitais, de acordo com a 
http://dx.doi.org/10.5902/1984686X37493

legislação educacional norte-americana implantada (IDEA, 1997). Há uma ressalva de que esse tipo de instrução deve ocorrer somente em casos extremos e bem específicos das condições de saúde do estudante, que ocasionem ausências intermitentes ou ausência por longos períodos, e que o serviço deve contar com o acompanhamento de uma equipe multidisciplinar para garantir o progresso acadêmico e o retorno precoce dos alunos à escola.

Holanda e Collet (2011) trazem as percepções das famílias de crianças hospitalizadas com doenças crônicas sobre o afastamento do processo de escolarização. Os dados encontrados revelam que as atividades educacionais desenvolvidas nas classes hospitalares acabam sendo confundidas pelos familiares como um momento de recreação. As autoras consideram as classes fundamentais para o atendimento aos estudantes hospitalizados e para proporcionar uma melhor qualidade de vida, especialmente àqueles com doença crônica, o que representa um avanço ao tratarmos do contexto brasileiro. Entretanto, as mesmas sinalizam que esse serviço precisa ter o apoio das Secretarias de Educação na provisão de recursos humanos, financeiros e materiais, consolidando-se como um direito, o que acaba sendo um impedimento para a implantação desse serviço conforme previsto em Lei (BRASIL, 2001; 2002; FONSECA, 2008).

Vieira e Lima (2002) apresentam, por meio de entrevistas, a experiência vivenciada pela criança e pelo adolescente com doença crônica. Os resultados revelam a mudança no cotidiano deles em decorrência das hospitalizações, bem como dos limites impostos tanto pela doença quanto pelo tratamento, ocasionando mudanças, especialmente no processo de escolarização. As autoras destacam a importância dos mecanismos de continuidade da escolarização, como as classes hospitalares, a fim de favorecer a aceitação e reintegração do aluno na escola, sem prejuízo nas atividades curriculares, corroborando Holanda e Collet (2011).

A última categoria, "Políticas Públicas", contempla uma pesquisa que discute as limitações das leis australianas que regulamentam os serviços aos estudantes com doenças crônicas, indicando as lacunas para o atendimento educacional a esse público (ASHTON; BAILEY, 2004). Para tanto, os autores analisam políticas federais e estaduais do país que tratam sobre o apoio às crianças em condições complexas de saúde. Destacam que as políticas acabam se limitando às necessidades oriundas das deficiências e que não abordam as adequações no ambiente, ao apoio às crianças ou 
http://dx.doi.org/10.5902/1984686X37493

sobre as práticas dos professores. Os autores sugerem que a "Política ideal" contemple todas as crianças com doenças crônicas e ofereça definições específicas de quais são essas doenças e suas possíveis complicações no processo de desenvolvimento infantil; apresente as informações paras as adaptações necessárias para essas crianças nos anos críticos do seu desenvolvimento, bem como os procedimentos para a sua implementação. Além disso, sugerem que deva ser oferecido um apoio às crianças logo na primeira infância com relação ao absenteísmo, para minimizar os impactos causados por essa experiência.

Ao analisar os vinte e dois artigos, pôde-se constatar que há algumas estratégias indicadas e ações que estão sendo realizadas visando proporcionar o atendimento educacional dos estudantes em situações complexas de saúde. Na tentativa de minimizar os impactos dos afastamentos para tratamento de saúde, bem como das consequências da própria condição, as propostas sinalizam para o atendimento educacional em classes hospitalares ou nas residências dos estudantes, para as situações mais graves. As aulas à distância também são indicadas, utilizando o recurso de videoconferência ou a comunicação e envio de atividades por e-mail. Há um reforço para o uso das aulas e atividades de educação física para possibilitar a melhoria na qualidade de vida dos estudantes.

Além dessas estratégias e ações, recomenda-se que um profissional presente na escola - como um conselheiro em educação hospitalar - possa fazer a intermediação entre família, escola e saúde, a fim de agilizar a comunicação e a implantação de um plano de ações interdisciplinar para -evitar maiores prejuízos no processo de escolarização.

\section{Considerações finais}

Mesmo em contextos tão diversos e em momentos distintos, como é possível observar pela variação dos anos de publicação, os trabalhos sinalizam os reflexos das condições complexas de saúde na vida acadêmica dos estudantes e na vida de seus familiares, bem como os desafios da equipe escolar em lidar com essas condições e evitar maiores prejuízos. Além disso, constata-se o comprometimento do desenvolvimento psicossocial daqueles estudantes, especialmente no estabelecimento de vínculos com os professores e seus pares e no sentimento de pertencimento à escola. 
http://dx.doi.org/10.5902/1984686X37493

As pesquisas também destacam a presença cada vez maior de estudantes com essas condições nas escolas - diabetes, câncer, epilepsia, artrite reumatoide, asma, HIV - considerando os avanços da ciência e da tecnologia no diagnóstico e tratamento das enfermidades, o que implica em mudanças nas formas de lidar com essa nova realidade e a necessidade de formação específica para os professores e demais membros da equipe escolar. É preciso que a equipe seja, por exemplo, capacitada a identificar os sintomas das doenças e os efeitos de seus tratamentos, para conduzir a vivência na escola daqueles estudantes de modo a proporcionar sua integridade física e psicossocial. Essa capacitação poderia ocorrer em serviço, pelas parcerias com as equipes de saúde que fazem os atendimentos dos alunos - enfermeiros, médicos, fisioterapeutas, terapeutas ocupacionais - e também pela discussão de manuais e cartilhas sobre as condições complexas de saúde mais comuns durante a idade escolar.

Havendo o conhecimento de toda a equipe sobre as condições dos estudantes, é possível também desenvolver práticas no âmbito escolar que possam diminuir o preconceito e a exclusão dos mesmos, além de minimizar os prejuízos em seu processo de escolarização. Como exemplos, podem ser citadas: a elaboração de um plano de trabalho específico, que envolva as atividades curriculares para serem realizadas em domicílio ou no hospital; a oferta do atendimento educacional especializado no contra turno; a oferta de recursos adaptados e estratégias didáticas diferenciadas para atender as suas necessidades; as adaptações nos espaços físicos da escola - como a disposição das carteiras na sala de aula - e as modificações em práticas e rotinas escolares - como o ajuste no horário de merenda, a organização dos passeios fora da escola, a realização de atividades ao ar livre.

Como apresentado nos resultados, alguns dos trabalhos analisados trazem ações que foram implementadas em determinados contextos e que surtiram efeitos positivos no processo de escolarização daqueles estudantes. Outras pesquisas indicam possíveis ações que tendem a minimizar o impacto da condição da doença e suas consequências na vida das crianças e adolescentes, o que ajudam a analisar as sugestões e refletir sobre as possibilidades de implantação das mesmas, considerando as demandas dos alunos.

Entretanto, os artigos indicam que há um caminho a percorrer para o cumprimento dos direitos dos estudantes em situações complexas de saúde, principalmente para evitar prejuízos em seu processo de escolarização. Como indicado inicialmente nesse trabalho, 
http://dx.doi.org/10.5902/1984686X37493

não há clareza nos sistemas de ensino sobre a quem recai a responsabilidade desse processo - se é ao professor de sala regular, se é ao professor de classe hospitalar, se é ao educador especial - e o atendimento educacional acaba não sendo ofertado para esses estudantes como previsto e garantido por lei.

Ainda, a realidade das escolas e dos sistemas de ensino como um todo, que muitas vezes não possuem recursos materiais e humanos para a efetivação das propostas de atendimento aos alunos: se planejada, por exemplo, uma atividade à distância, como uma videoaula ou videoconferência, para proporcionar o acesso imediato ao estudante afastado para tratamento de saúde do conteúdo trabalhado em sala, é preciso garantir equipamento computador com câmera, notebook ou tablete - internet em sala de aula e na residência do aluno ou no hospital, bem como a orientação ao professor para que saiba utilizar as tecnologias. Ou se considerada uma classe hospitalar na qual o professor não tenha comunicação com a escola de origem dos estudantes, ou então, desprovida de materiais didáticos, dificilmente será garantida a continuidade do processo de escolarização.

Pode-se dizer que há consenso nos estudos analisados sobre a importância da comunicação e da colaboração entre família, escola e equipe de saúde para um efetivo processo educacional desse público. Para que essa comunicação e colaboração ocorram algumas medidas podem ser tomadas, como a presença de um profissional (um professor, um conselheiro ou um mentor) intermediando e facilitando esse processo. Esse profissional, pelo vínculo que teria com os demais das outras áreas, poderia elaborar relatórios para informar a condição dos estudantes tanto para a escola, para a família, quanto para os profissionais de saúde, na tentativa de melhorar a condição dos estudantes: sinalizar, por exemplo, os momentos em que os alunos estão mais ou menos dispostos em decorrência da medicação tomada em determinado horário, para ajustar essa rotina e melhorar a vivência dos mesmos na escola. Esse mesmo profissional poderia auxiliar na organização da agenda para consultas e procedimentos em geral para que não houvesse a concentração de ausências na escola no mesmo dia da semana ou período em que os estudantes estão matriculados.

Nessa direção, reitera-se a importância de políticas públicas na área da educação e também na saúde que reforcem e viabilizem o cumprimento dos direitos dos estudantes. Mesmo que existam leis que preveem o atendimento educacional ao estudante em tratamento de saúde, são necessárias as diretrizes que regulem e operacionalizam a organização desse serviço, como uma forma de garantir a continuidade do processo de 
http://dx.doi.org/10.5902/1984686X37493

escolarização, sem prejuízos na vida acadêmica dos estudantes em condições complexas de saúde.

\section{Referências}

AMERICAN ACADEMY OF PEDIATRICS. Committee on Pediatric AIDS. Education of Children With Human Immunodeficiency Virus Infection. PEDIATRICS. Vol. 105, n. 6, jun. 2000a. Disponível em: http://pediatrics-aappublications-

org.ez31.periodicos.capes.gov.br/content/pediatrics/105/6/1358.full.pdf. Acesso em: 26 set. 2018.

AMERICAN ACADEMY OF PEDIATRICS. Committee on School Health Home, Hospital, and Other Non-School-based Instruction for Children and Adolescents Who Are Medically Unable to Attend School. PEDIATRICS. Vol. 106, n. 5, p. 1154, nov. 2000b. Disponível em: http://pediatrics-aappublicationsorg.ez31.periodicos.capes.gov.br/content/106/5/1154. Acesso em: 10 ago. 2018.

ASHTON, Jean; BAILEY, Jeff. Slipping through the policy cracks: children with chronic illness in early childhood settings. Australian Journal of Early Childhood March, 2004, Vol. 29, n. 1, p.50(9). Disponível em: http://gogalegroup.ez31.periodicos.capes.gov.br/ps/i.do?\&id=GALE|A118416772\&v=2.1\&u=capes\&it= $\mathrm{r} \& \mathrm{p}=\mathrm{AONE} \& \mathrm{sw}=\mathrm{w}$. Acesso em: 15 ago. 2018.

BARRIOS-HERNANDEZ, Yanquiel. Calidad de vida y entorno escolar del nino con epilepsia. Revista Educación, Costa Rica, Vol.37, n. 2, p.143(12), 2013. Disponível em: http://gogalegroup.ez31.periodicos.capes.gov.br/ps/i.do?\&id=GALE $\mid A 450362785 \& v=2.1 \& u=$ capes\&it= $\mathrm{r} \& \mathrm{p}=\mathrm{AONE} \& \mathrm{sw}=\mathrm{w}$. Acesso em: 27 ago. 2018.

BERGER, Carolyn. et al. School Professionals' Knowledge and Beliefs About Youth With Chronic Illness. Journal of School Health. Vol.88, n. 8, pp.615-623, Ago. 2018. Disponível em: https://onlinelibrary-wiley.ez31.periodicos.capes.gov.br/doi/full/10.1111/josh.12646. Acesso em: 05 set. 2018.

BRAGA, Tania Moron Saes; BOMFIM, Diogo Pazzani; SABBAG FILHO, Daher. Necessidades especiais de escolares com diabetes mellitus tipo 1 identificadas por familiares. Rev. bras. educ. espec. Marília, v. 18, n. 3, p. 431-448, Set. 2012. Disponível em: http://www.scielo.br/scielo.php?script=sci_arttext\&pid=S1413-65382012000300006. Acesso em 27 jun. 2018.

BRASIL. Constituição (1988). Constituição da República Federativa do Brasil. Brasília, DF: Senado Federal: Centro Gráfico, 1988. 292. Disponível em: https://www.planalto.gov.br/ccivil_03/constituicao/constituicao.htm. Acesso em: 15 jul. 2018.

BRASIL. Ministério da Justiça. Lei no 8.069/1990, de 13 de julho de 1990. Dispõe sobre o Estatuto da Criança e do Adolescente e dá outras providências. Disponível em: http://www.planalto.gov.br/ccivil_03/leis/L8069.htm. Acesso em: 15 jul. 2018. 
BRASIL. Coordenadoria Nacional para a Integração de Pessoa Portadora de Deficiência. Declaração de Salamanca e Linha de ação sobre necessidades educativas especiais. Brasília, DF, 1994. Disponível em:

http://portal.mec.gov.br/seesp/arquivos/pdf/salamanca.pdf. Acesso em: 22 jul. 2018.

BRASIL. Ministério de Educação e do Desporto. Lei de Diretrizes e Bases da Educação Nacional - Lei no 9394/96, de 20 de dezembro de 1996. Estabelece as diretrizes e bases da Educação Nacional. Disponível em: https://www.planalto.gov.br/ccivil_03/Leis/L9394.htm. Acesso em 20 jul. 2018.

BRASIL. Ministério da Justiça. Decreto no 3.298, de 20 de dezembro de 1999. Regulamenta a Lei no 7.853, de 24 de outubro de 1989, dispõe sobre a Política Nacional para a Integração da Pessoa Portadora de Deficiência, consolida as normas de proteção, e dá outras providências. Disponível em: http://www.planalto.gov.br/ccivil_03/decreto/d3298.htm. Acesso em: 18 abr. 2018.

BRASIL. Conselho Nacional de Educação. Câmara de Educação Básica. Resolução CNE/CEB nº 02, de 11 de setembro de 2001. Institui as Diretrizes Nacionais para a Educação Especial na Educação Básica. Disponível em http://portal.mec.gov.br/cne/arquivos/pdf/CEB0201.pdf. Acesso em: 28 jul. 2018.

BRASIL. Ministério da Educação. Classe hospitalar e atendimento pedagógico domiciliar: estratégias e orientações. Secretaria de Educação Especial. Brasília: MEC; SEESP, 2002.

BRASIL. Ministério da Educação. Decreto no 7.611, de 17 de novembro de 2011. Dispõe sobre a Educação Especial, o Atendimento Educacional Especializado e dá outras providências. Disponível em: http://www.planalto.gov.br/ccivil_03/_ato20112014/2011/decreto/d7611.htm. Acesso em: 02 abr. 2018.

CASTRO, Elisa Kern de; PICCININI, César Augusto. Implicações da doença orgânica crônica na infância para as relações familiares: algumas questões teóricas. Psicologia: reflexão e crítica, Porto Alegre, v. 15, n. 3, p. 625-635, 2002. Disponível em:

http://www.scielo.br/scielo.php?pid=S0102-79722002000300016\&script=sci_abstract\&tlng=pt. Acesso em: 20 jul. 2018.

COSTA, Angelo Brandelli; ZOLTOWSKI, Ana Paula Couto. Como escrever um artigo de revisão sistemática. In: KOLLER, Silvia H.; COUTO, Maria Clara P. de Paula; HOHENDORFF, Jean Von (orgs) Manual de produção científica. Porto Alegre: Penso, 2014.

DePAEPE, Paris; GARRISON-KANE, Linda; DOELLING, Jane. Supporting students with health needs in schools: an overview of selected health conditions. Focus on exceptional children, Denver, v.35, n.1, sep. 2002. Disponível em:

https://search.proquest.com/openview/ba7e66479a17c536ed501b4550027deb/1?pqorigsite=gscholar\&cbl=48488. Acesso em: 22 jul. 2018.

ESTADOS UNIDOS DA AMÉRICA. Departamento de Educação. Lei nํ105-17 de 4 de junho de 1997 - Individuals with Disabilities Education Act Amendments. 1997. Disponível em: https://www2.ed.gov/about/offices/list/oii/nonpublic/idea1.html. Acesso em: 19 nov.19. 
FONSECA, Eneida Simões da. Atendimento Escolar no Ambiente Hospitalar. 2ª ed. São Paulo: Memnon, 2008.

GARCIA, Ligia Rejane Siqueira. et al. Conhecimento sobre diabetes mellitus entre profissionais da rede pública de ensino. Rev Bras Promoç Saúde. Fortaleza, Vol. 30, n. 1. p. 57-63, jan./mar., 2017. Disponível em: http://periodicos.unifor.br/RBPS/article/view/5455. Acesso em: 17 set. 2018.

GELABERT, Sebastià Verger; RAMON, Maria Rosa Rosselló; MAYOL, Begoña De La Iglesia. Educación Física y atención al alumnado con enfermedad crónica en la escuela. Revista de Psicología del Deporte. Universitat de les Illes Balears, Espanha, Vol.25, n. 1, pp.195-200, 01 jan. 2016. Disponível em:

https://doaj.org/article/d786dca243ae43798fb09560e32650fa?gathStatlcon=true. Acesso em: 04 set. 2019.

GOLDFELD, Sharon. et al. Learning Trajectories of Children With Special Health Care Needs Across the Severity Spectrum. Academic Pediatrics Vol.15, n. 2, pp.177-184, March-April 2015. Disponível em: https://wwwsciencedirect.ez31.periodicos.capes.gov.br/science/article/pii/S1876285914003258. Acesso em: 16 set. 2018.

HOLANDA, Eliane Rolim de. Doença Crônica na Infância e o Desafio do Processo de Escolarização: Percepção da Família. 2008. 116f. Dissertação (Mestrado em Enfermagem). Centro de Ciências da Saúde, Universidade Federal da Paraíba, João Pessoa. Disponível em: http://www.ccs.ufpb.br/ppgeold/dissertacoes2008/dissertacaoelianerolim.pdf. Acesso em: 15 jul. 2018.

HOLANDA, Eliane Rolim de; COLLET, Neusa. As dificuldades da escolarização da criança com doença crônica no contexto hospitalar. Rev. Esc. Enf. USP São Paulo, vol.45, n.2, abr. 2011. Disponível em: http://www.scielo.br/scielo.php?script=sci_arttext\&pid=S008062342011000200012. Acesso em: 04 ago. 2018.

HAMLET, Helen S.; GERGAR, Patricia G.; SCHAEFER, Barbara A. Students Living with Chronic Illness: The School Counselor's Role. Professional School Counseling, Vol.14, n.3, p.202-210, 2011. Disponível em:

https://journals.sagepub.com/doi/pdf/10.1177/2156759X1101400304. Acesso em: 05 ago. 2018.

KAFFENBERGER, Carol J. School reentry for students with a chronic illness: a role for professional school counselors. Professional School Counseling. Vol. 9, n. 3, p.223 (8), feb, 2006. Disponível em: http://go-

galegroup.ez31.periodicos.capes.gov.br/ps/i.do?\&id=GALE|A142682714\&v=2.1\&u=capes\&it= $\mathrm{r} \& \mathrm{p}=\mathrm{AONE} \& \mathrm{sw}=\mathrm{w}$. Acesso em: 05 ago. 2018.

KUCZYNSKI, Evelyn. Avaliação da qualidade de vida em crianças e adolescentes sadios e portadores de doenças crônicas e/ou incapacitantes. 2002. 211f. Tese (Doutorado em Medicina) - Faculdade de Medicina, Universidade de São Paulo, São Paulo. Disponível em: http://www.teses.usp.br/teses/disponiveis/5/5142/tde-20062007-155800/ptbr.php. Acesso em: 28 jul. 2018. 
LARCOMBE, Isobel J. et al. Impact of childhood cancer on return to normal school. British Medical Journal. July 21, 1990, Vol.301, n. 6744, p.169(3). Disponível em: https://www.bmj.com/content/301/6744/169.short. Acesso em: 10 set. 2018.

MOREIRA, Geraldo Eustáquio. SALLA, Helma. O Atendimento Pedagógico Domiciliar de alunos que não podem frequentar fisicamente a escola por motivos de saúde: revisão sistemática das investigações realizadas entre 2002 e 2015. Revista Educação Especial, v. 31, n. 60, p. 119-138, jan./mar. 2018. Disponível em:

https://periodicos.ufsm.br/educacaoespecial. Acesso em: 10 ago. 2018.

MOURA, Raissa Gomes Fonseca. et al. Prevalência dos fatores intrínsecos e extrínsecos do processo de aprendizagem em crianças com epilepsia. Rev. CEFAC. São Paulo. vol. 16, n. 2, p. 472-478. Mar-abr, 2014.Disponível em:

http://gogalegroup.ez31.periodicos.capes.gov.br/ps/i.do?id=GALE\%7CA450999843\&v=2.1\&u $=$ capes\&it=r\&p=AONE\&sw=w. Acesso em: 10 ago. 2018.

NASCIMENTO, Fabiana Ferreira do; YAAKOUB, Melissa Cavalcanti; AQUINO, Celeste Maria. Educação, Saúde e Inclusão: conhecendo as histórias de vidas de pessoas com febre reumática. Revista Periferia. Rio de Janeiro, Vol. 9, n.1, pp.86-111, 01 jun. 2017. Disponível em: http://www.epublicacoes.uerj.br/index.php/periferia/article/view/28956/20720. Acesso em: 02 set. 2018.

NASCIMENTO, Lucila Castanheira. Crianças com câncer: a vida das famílias em constante reconstrução. 2003. 233f. Tese (Doutorado em Enfermagem) - Escola de Enfermagem de Ribeirão Preto, Universidade de São Paulo, Ribeirão Preto, 2003.

ORGANIZAÇÃO PAN-AMERICANA DE SAÚDE. O conceito de condições de saúde. Texto elaborado com base no agrupamento de partes literalmente extraídas do livro MENDES, Eugenio Vilaça. $\mathbf{O}$ cuidado das condições crônicas na atenção primaria à saúde: 0 imperativo da consolidação da estratégia da saúde da família. Brasília: 2012. Disponível em: https://www.nescon.medicina.ufmg.br/biblioteca/imagem/4096.pdf. Acesso em: 13 abr. 2018.

PILGER, Calíope; SCHROEDER ABREU, Isabella. Diabetes Mellitus na infância: repercussões no cotidiano da criança e de sua família. Cogitare Enfermagem, vol. 12, n. 4, out-dez./2007, p. 494-501. Universidade Federal do Paraná, Curitiba. Disponível em: http://www.redalyc.org/articulo.oa?id=483648985012. Acesso em: 23 ago. 2018.

SHIU, Shiona. Issues in the Education of Students with Chronic IIIness. International Journal of Disability, Development \& Education. Sep 2001, Vol. 48 Issue 3, p269-281. 13p.

Disponível em: http://web.b-ebscohostcom.ez31. periodicos.capes.gov.br/ehost/pdfviewer/pdfviewer?vid=1\&sid=5664e1f9-9d73-42ffbfad-b0c3cabf1824\%40pdc-v-sessmgr04. Acesso em: 15 ago. 2018.

SHIU, Shiona. Positive Interventions for Children with Chronic Illness: Parents' and Teachers' Concerns and Recommendations. Australian Journal of Education. Vol. 48, n.3, pp.239252, nov. 2004. Disponível em: https://go.gale.com/ps/i.do?p=AONE\&u=capes\&id=GALE|A124791655\&v=2.1\&it=r. Acesso em: 15 ago. 2018. 
SURIS, Joan-Carles; MICHAUD, Pierre-André; VINER, Russel. The adolescent with a chronic condition. Part I: developmental issues. Archives of Disease in Childhood. Vol. 89, n.10, p.938, oct. 2004. Disponível em: https://adc-bmjcom.ez31.periodicos.capes.gov.br/content/archdischild/89/10/938.full.pdf?frbrVersion=5. Acesso em: 20 jul. 2018.

TARAS, Howard; BRENNAN, Jesse J. Students with chronic diseases: nature of school physician support. Journal of School Health. Vol.78, n. 7, p.389 (8), jul. 2008. Disponível em: https://onlinelibrary-wiley.ez31.periodicos.capes.gov.br/doi/full/10.1111/j.17461561.2008.00319.x. Acesso em: 31 ago. 2018.

THIES, Kathleen M. Identifying the Educational Implications of Chronic Illness in School Children. Journal of School Health. Vol. 69, n. 10, p.392, dec. 1999. Disponível em: https://onlinelibrarywiley.ez31.periodicos.capes.gov.br/doi/full/10.1111/j.17461561.1999.tb06354.x. Acesso em: 10 set. 2018.

UNESCO. Declaração mundial sobre educação para todos. Plano de ação para satisfazer as necessidades básicas de aprendizagem. Jomtien, Tailândia, 1990. Disponível em: http://unesdoc.unesco.org/images/0008/000862/086291 por.pdf. Acesso em: 24 jul. 2018.

UNESCO. Coordenadoria Nacional para a Integração de Pessoa Portadora de Deficiência. Declaração de Salamanca e Linha de ação sobre necessidades educativas especiais. Brasília, DF, 1994. Disponível em:

http://portal.mec.gov.br/seesp/arquivos/pdf/salamanca.pdf Acesso em: 22 ago. 2018

VIEIRA, Maria Aparecida; LIMA, Regina Aparecida Garcia de. Crianças e adolescentes com doença crônica: convivendo com mudanças. Rev. Latino-Am. Enfermagem. Ribeirão Preto, v. 10, n. 4, p. 552-560, jul. 2002. Disponível em:

http://www.scielo.br/scielo.php?script=sci_arttext\&pid=S0104-11692002000400013. Acesso em: 10 ago. 2018.

WILKIE, Karina J. Absence Makes the Heart Grow Fonder: Students with Chronic Illness Seeking Academic Continuity through Interaction with Their Teachers at School.

Australasian Journal of Special Education. Vol. 36, n.1, p.1-20, 2012. Disponível em: https://www-cambridge.ez31.periodicos.capes.gov.br/core/journals/australasian-journal-ofspecial-education/article/absence-makes-the-heart-grow-fonder-students-with-chronic-illnessseeking-academic-continuity-through-interaction-with-their-teachers-atschool/09B7FCC610450EABC7087BC03A0E8AF4.

\section{Notas}

1 Os artigos encontrados com esse termo abrangiam diversas áreas do conhecimento, o que não era objetivo da pesquisa. Optou-se por aplicar os seguintes filtros, para refinar ainda mais a busca: Children, Education, Child Health, Health, Humans. A busca com esses tópicos marcados retornou 385 trabalhos. 


\section{Correspondência}

Mariana Cristina Pedrino - Universidade Federal de São Carlos, Centro de Educação e Ciências Humanas, Programa de Pós-graduação em Educação Especial. Rodovia Washington Luís, km 235, São Carlos, São Paulo - Brasil.

CEP: $13565-905$

\section{(c) $($ ) 8 (3)}

This work is licensed under a Creative Commons Attribution-NonCommercial 4.0 International (CC BY-NC 4.0) 